Research Article

\title{
Performance Evaluation of Waste Crumb Rubber/Silica Fume Composite Modified Pervious Concrete in Seasonal Frozen Regions
}

\author{
Guobao Luo $\mathbb{D}^{1,2}$, Pin Zhao $\mathbb{D}^{2}{ }^{2}$ Yangpeng Zhang, ${ }^{3,4}$ and Zhengzhuan Xie ${ }^{3,4}$ \\ ${ }^{1}$ State Key Laboratory of Mechanical Behavior and System Safety of Traffic Engineering Structures, \\ Shijiazhuang Tiedao University, Shijiazhuang 050043, China \\ ${ }^{2}$ Key Laboratory of Roads and Railway Engineering Safety Control (Shijiazhuang Tiedao University), Ministry of Education, \\ Shijiazhuang 050043, China \\ ${ }^{3}$ Guangxi Transportation Science \& Technology Group Co. Ltd., Nanning 5300007, China \\ ${ }^{4}$ Guangxi Key Lab of Road Structure and Materials, Nanning 5300007, China
}

Correspondence should be addressed to Pin Zhao; zhaopin1115@126.com

Received 22 April 2021; Revised 7 June 2021; Accepted 16 June 2021; Published 24 June 2021

Academic Editor: Xiao Dong Zhao

Copyright (c) 2021 Guobao Luo et al. This is an open access article distributed under the Creative Commons Attribution License, which permits unrestricted use, distribution, and reproduction in any medium, provided the original work is properly cited.

\begin{abstract}
The waste crumb rubber (WCR) and silica fume (SF), as industrial waste and byproduct, are widely used as additives in road construction materials, which can not only realize waste utilization and protect the environment but also reduce the consumption of building material resources. At present, most of the research has focused on the properties of concrete modified only by WCR or SF; there are few studies concentrated on composite modified concrete by the two, especially the study on pervious concrete (PC). This article aims to study the mechanical strength, deformability, and freeze-thaw (F-T) resistance of waste crumb rubber/silica fume composite modified pervious concrete (RSFPC). The RSFPC and control specimens were manufactured in the lab. The experiments of compressive strength, flexural strength, flexural failure strain, flexural elastic modulus, and F-T cycles were conducted. In addition, the properties of RSFPC were compared with WCR and SF single modification PC. The results indicate that the composite modification of WCR and SF can give full play to the advantages of the two materials so that the strength property and elastic modulus of PC will not be decreased and the F-T resistance and deformability can be greatly improved. Compared to a single modification group by WCR or SF, RSFPC has a more balanced and comprehensive performance, which will greatly expand the application of PC.
\end{abstract}

\section{Introduction}

In the process of urbanization, the unprecedented levels of urbanization not only brings great convenience to people's life but also causes many social and environmental problems $[1-3]$. Due to the excessive consumption of natural resources and the increase of carbon emissions, global climate change is becoming more and more obvious. Extreme severe weather conditions such as high temperature and flood frequently occur [4-6]. At the same time, the urban surface is covered by a dense concrete structure, which blocks the flow of water and gas between underground and ground, causing many urban problems, such as urban waterlogging, groundwater recession, noise pollution, and urban heat island phenomenon [7-10]. With the increasing prominence of urban problems and people's awareness of environmental protection, it has become the focus of people's attention to construct green and sustainable development of city-peopleenvironment. Thus, China has proposed the concept of sponge city in 2012 [11]. In 2015, the first batch of sponge city construction pilot city was determined, and 16 cities were shortlisted. Meanwhile, state finance provided 10 billion CNY as support.

The most important component of sponge city construction is urban pervious pavement; it is a kind of pavement structure with connected pores that can realize the 
functions of being permeable and breathable. It can well solve the urban problems brought by impervious pavement, and it is an ecological and environmental protection pavement structure $[12,13]$. Compared with the traditional impervious pavement structure, the pervious pavement has several advantages: (1) raising the groundwater level and replenish groundwater resources, (2) reducing urban surface runoff and alleviate urban waterlogging, (3) reducing urban noise pollution and improving urban living environment, and (4) alleviating urban heat island phenomenon and improving the urban ecological environment. At present, PC is widely used in parks, sidewalks, light vehicle roads, and squares [14-16]. Generally speaking, the permeability and compressive strength of $\mathrm{PC}$ can meet the engineering requirements [17-20]. However, when PC is used as road surface or base layer, it will often be subjected to the repeated vehicle loads, which requires that PC not only has sufficient strength but also has certain deformability to resist fatigue [21]. Moreover, the porous structure of PC makes the adverse effect of F-T more serious than that of ordinary concrete. So, the F-T resistance of PC is also very important $[22,23]$. Therefore, good deformability and F-T resistance for PC in seasonal frozen regions are as important as permeability and strength property.

WCR has been widely used in road engineering for its high toughness and antiaging properties. The application of WCR in ordinary concrete shows that WCR can effectively improve the deformation property, F-T resistance, toughness, vibration, and noise reduction performance of concrete, but it has a negative impact on its strength [24-28]. SF, as a byproduct of the smelting industry with abundant silica, is an excellent cement-based modified material and has a broad application prospect in cement concrete $[29,30]$. The research has already verified that the addition of SF can significantly improve the strength and F-T resistance of concrete [31, 32].

Although mature and extensive research has been conducted on the application of WCR or SF in ordinary concrete, their application in PC is rarely reported, especially the modification with two kinds of materials simultaneously. The researches on rubberized PC showed that the addition of WCR significantly decreased the mechanical properties and abrasion resistance, but it had a crucial positive effect on the ductility and vibration reduction performance of $\mathrm{PC}$ $[33,34]$. In addition, the properties of rubberized PC were pertinent to the particle size of WCR. The adverse effect of fine rubber on mechanical properties was less than that of coarse rubber. At the same time, the positive influence of fine rubber on deformability was better than that of coarse rubber $[35,36]$. Therefore, the WCR with relatively small particles is the preference in modifying pervious concrete, which is different from ordinary concrete. In terms of SF, it had been verified that the SF-reinforced PC had great advantages in mechanical strength and durability, but the deformability was not improved [37-39]. The compressive strength of PC, with $10 \%$ SF replacement, had been greatly improved by more than $80 \%$ [38]; this great increase in compressive strength was worthy of further study to verify. The properties of PC modified or reinforced with WCR or
SF, on the whole, need to be studied extensively and indepth.

Based on the current research progress, a large number of studies on WCR or SF single modification concrete have been conducted by domestic and foreign scholars, and considerable research findings were achieved. It can be seen that, due to the high elasticity of WCR, the addition of it can significantly improve the deformability of concrete under load, thus improving concrete toughness. At the same time, the addition of WCR will weaken the bonding between concrete components, resulting in the reduction of concrete strength. The rich silica content of SF leads to a further chemical reaction between SF and cement hydration products to produce a stronger gel, which improves the strength and durability of concrete. PC, as pavement material in practical engineering, requires not only sufficient strength to bear the action of load but also good deformability to bear the action of repeated load. In addition, the frost resistance of PC is the most important index of durability when it is used in seasonal frozen regions. Therefore, the development of PC with good deformability, superior frost resistance, and high strength is an important basis for the application. Considering the advantages of WCR or SF, in order to give full play to the characteristics of both materials, combined with previous research performed by our group [30, 35], this article conducted the laboratory investigation on the mechanical property and $\mathrm{F}$-T resistance of RSFPC. The research outline is shown in Figure 1.

\section{Experimental Materials and Methods}

2.1. Raw Materials. The ordinary Portland cement of 42.5 and SF were used as cementitious materials for RSFPC. The coarse aggregate with $4.75-9.5 \mathrm{~mm}$ and WCR with a particle size of 40 mesh, obtained from a local factory, were selected in the article. The technical properties of all the above materials can be found in $[30,35]$. Besides, a superplasticizer was applied and its properties are listed in Table 1. The experiment water is tap water.

2.2. Mix Design. With equal volume replacement of cement, the effect of different SF contents on the properties of PC has been studied by our group [30]. The research indicated that $12 \%$ SF presented better modification effectiveness, so in this study, the SF incorporation level was selected as $12 \%$. In addition, the effect of particle size of WCR on the properties of PC indicated that the fine WCR showed better improvement than that of the coarse WCR [35], so the fine WCR was selected and the incorporation level of WCR for RSFPC was set as $4 \%, 6 \%$, and $8 \%$ of cementitious material quality. The volumetric method was adopted to design RSFPC in accordance with the Chinese national standard [40]. The water-to-binder ratio was 0.3 , and the designed porosity was $15 \%$. The content of the superplasticizer was $0.8 \%$. The mix design is shown in Table 2 .

2.3. Specimen Preparation and Test Methods. The preparation method, the production, and curing condition of RSFPC specimens have been reported in detail in [21]. The 


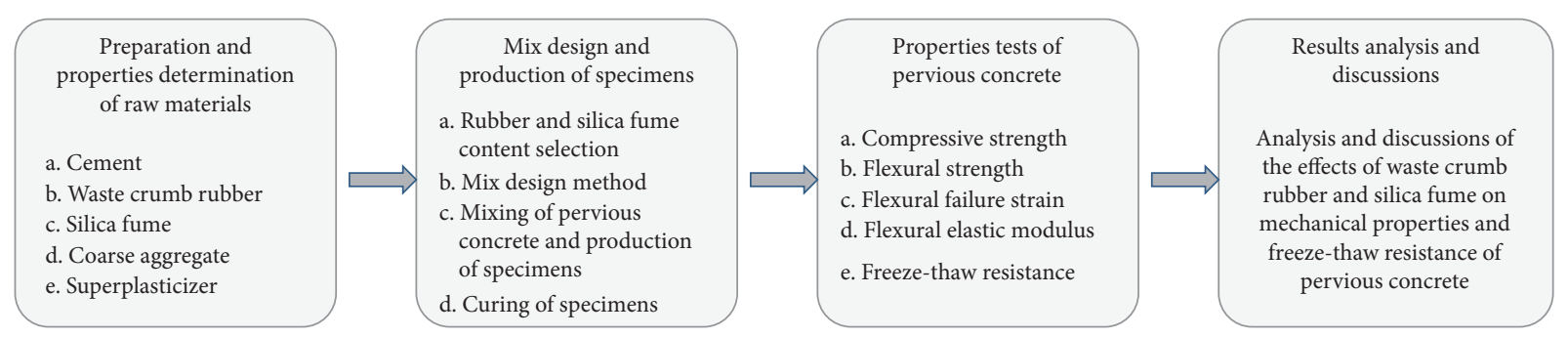

FIgURE 1: The research outline of the article.

TABLE 1: Technical index of superplasticizer.

\begin{tabular}{lccc}
\hline Uniformity parameters & & Properties parameters \\
\hline Morphology & Liquid & Water-reducing rate (\%) & \\
pH & $7.0-8.0$ & Air content (\%) & 1.5 \\
Density $\left(\mathrm{kg} / \mathrm{m}^{3}\right)$ & $0.98-1.02$ & Difference between initial setting times (min) & +35 \\
Effective content (\%) & $20-25$ & Difference between final setting times (min) & +50 \\
Chloride ion content (\%) & 0.01 & $7 \mathrm{~d}$ compressive strength ratio (\%) & 163 \\
Alkali content (\%) & 0.02 & $28 \mathrm{~d}$ compressive strength ratio (\%) & 159 \\
\hline
\end{tabular}

TABle 2: Mix design of RSFPC (in $\mathrm{kg} / \mathrm{m}^{3}$ ).

\begin{tabular}{|c|c|c|c|c|c|c|c|c|}
\hline Mix ID & WCR content (\%) & SF content (\%) & Coarse aggregate & Cement & Water & PAS 1 & WCR & SF \\
\hline WCR $4+$ SF12 & 4 & 12 & 1503 & 413.0 & 140.8 & 3.75 & 18.8 & 56.3 \\
\hline WCR6 + SF12 & 6 & 12 & 1503 & 413.0 & 140.8 & 3.75 & 28.2 & 56.3 \\
\hline $\mathrm{WCR} 8+\mathrm{SF} 12$ & 8 & 12 & 1503 & 413.0 & 140.8 & 3.75 & 37.5 & 56.3 \\
\hline
\end{tabular}

${ }^{1}$ Polycarboxylic acid superplasticizer.

sizes of the specimens are as follows: cube specimen with $100 \times 100 \times 100 \mathrm{~mm}$ for compressive strength and F-T cycles tests; prism specimen with $100 \times 100 \times 400 \mathrm{~mm}$ for flexural experiments. All experiments were conducted according to GB/T 50081-2002 and 50082-2009 [41, 42]. The test method for rapid freeze-thaw was adopted. The freezing time was about 2.5 hours and the thawing time was about 1.5 hours. The lowest and highest temperatures in the center of the specimen were $-18^{\circ} \mathrm{C}$ and $5^{\circ} \mathrm{C}$, respectively. As shown in Figure 2, a three-point bending test is adopted for the flexural experiment. In order to accurately determine the flexural failure strain and flexural elastic modulus of RSFPC, the midspan displacement of the three-point bending specimen under load was recorded by a micrometer gauge placed on the bottom of the specimen. The flexural failure strain and flexural elastic modulus can be calculated by

$$
\begin{aligned}
& \varepsilon=\frac{6 h \Delta}{L^{2}}, \\
& E=\frac{L^{3}\left(F_{0.5}-F_{0}\right)}{4 B h^{3}\left(\Delta_{0.5}-\Delta_{0}\right)},
\end{aligned}
$$

where $\varepsilon$ is the flexural failure strain; $\Delta$ is the deflection corresponding to flexural failure load ( $\mathrm{mm}) ; E$ is the flexural elastic modulus $(\mathrm{GPa}) ; F_{0.5}$ is the load that equals $50 \%$ flexural failure load $(\mathrm{kN}) ; F_{0}$ is the initial load of the specimen and its value can be taken as the actual load of the specimen nearest to $2 \mathrm{kN}(\mathrm{kN})$; and $\Delta_{0.5}$ and $\Delta_{0}$ are the displacements of the specimen corresponding to $F_{0.5}$ and $F_{0}$ (mm).

\section{Experiments Results and Analysis}

3.1. Experiments Results. All the property indexes of RSFPC are expressed as the average value of three specimens; the experiments results are listed in Tables 3-7.

3.2. Properties Analysis of RSFPC. In order to analyze the compound modification effectiveness of WCR and SF, the control group (without WCR and SF), WCR group (WCR modification group), and SF group (SF modification group) are introduced as comparative groups. The data of the control group, WCR group, and SF group are obtained from the previous research conducted by our team.

3.2.1. Compressive Strength. Figure 3 shows the compressive strength of RSFPC and comparative groups. It indicates that the compressive strength of RSFPC decreases with the increase of WCR contents, which means the addition of WCR has an adverse impact on the compressive strength of PC. The result is consistent with that of the WCR single modification PC reported in [35]. This is because the WCR on the interfacial transition zone weakens the cementation between cement and coarse aggregate and thus decreases the bond force. Compared with WCR groups, due to the 

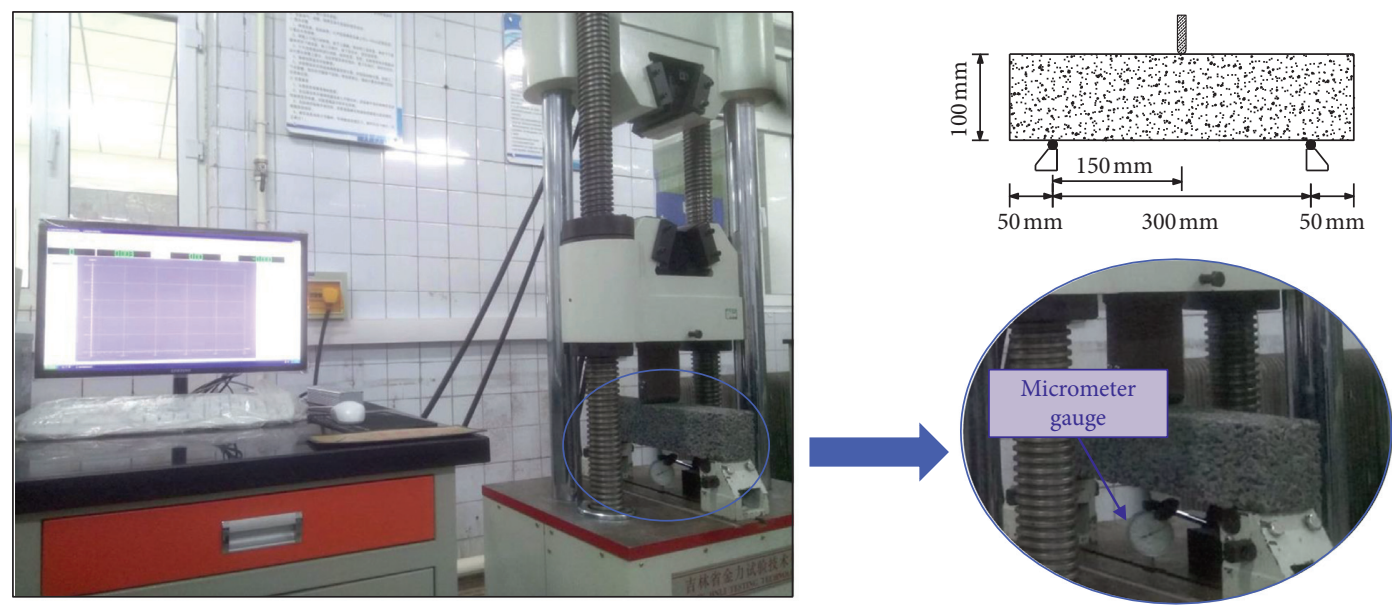

FIGURE 2: Three-point bending test.

TABLE 3: Compressive strength of RSFPC.

\begin{tabular}{lccccc}
\hline \multirow{2}{*}{ Mix ID } & \multicolumn{3}{c}{ Compressive strength (MPa) } & Mean & St. dev. \\
& 1 & 2 & 3 & 24.4 & 0.67 \\
WCR4+SF12 & 23.9 & 22.8 & 23.7 & 23.0 & 0.54 \\
WCR6 + SF12 & 22.4 & 22.9 & 19.1 & 19.9 & 0.59 \\
WCR8 + SF12 & 20.5 & 20.1 & & & \\
\hline
\end{tabular}

TABLE 4: Flexural strength of RSFPC.

\begin{tabular}{lccccc}
\hline \multirow{2}{*}{ Mix ID } & \multicolumn{3}{c}{ Flexural strength (MPa) } & Mean & St. dev. \\
& 1 & 2 & 3 & 4.68 & 0.08 \\
WCR4+SF12 & 4.78 & 4.59 & 4.66 & 4.59 & 0.05 \\
WCR6 + SF12 & 4.52 & 4.61 & 3.95 & 4.04 & 0.07 \\
WCR8 + SF12 & 4.11 & 4.05 & & 4.65 & \\
\hline
\end{tabular}

TABLE 5: Flexural failure strain of RSFPC.

\begin{tabular}{lccccc}
\hline \multirow{2}{*}{ Mix ID } & \multicolumn{3}{c}{ Flexural failure strain $(\mu \varepsilon)$} & Mean & St. dev. \\
\hline WCR4+ SF12 & 1 & 2 & 3 & 1511 & 1513 \\
WCR6 + SF12 & 1546 & 2098 & 2174 & 2155 \\
WCR8 + SF12 & 2194 & 2381 & 2375 & 2386 & 41 \\
\hline
\end{tabular}

TABLE 6: Flexural failure strain of RSFPC.

\begin{tabular}{|c|c|c|c|c|c|c|c|c|}
\hline \multirow{2}{*}{ Mix ID } & \multicolumn{8}{|c|}{ Flexural elastic modulus (GPa) } \\
\hline & Number & $F_{0.5}$ & $F_{0}$ & $\Delta_{0.5}$ & $\Delta_{0}$ & $E$ & Mean & St. dev. \\
\hline \multirow{3}{*}{$\mathrm{WCR} 4+\mathrm{SF} 12$} & 1 & 5.311 & 1.992 & 0.152 & 0.143 & 24.9 & \multirow{3}{*}{24.0} & \multirow{3}{*}{0.68} \\
\hline & 2 & 5.102 & 2.002 & 0.148 & 0.139 & 23.3 & & \\
\hline & 3 & 5.179 & 1.997 & 0.152 & 0.143 & 23.9 & & \\
\hline \multirow{3}{*}{ WCR6 + SF12 } & 1 & 5.021 & 1.995 & 0.152 & 0.142 & 20.4 & \multirow{3}{*}{20.9} & \multirow{3}{*}{0.36} \\
\hline & 2 & 5.119 & 1.999 & 0.151 & 0.141 & 21.1 & & \\
\hline & 3 & 5.156 & 2.003 & 0.154 & 0.144 & 21.3 & & \\
\hline \multirow{3}{*}{ WCR8 + SF12 } & 1 & 4.566 & 1.989 & 0.159 & 0.147 & 14.5 & \multirow{3}{*}{14.4} & \multirow{3}{*}{0.26} \\
\hline & 2 & 4.502 & 2.001 & 0.163 & 0.151 & 14.1 & & \\
\hline & 3 & 4.389 & 1.997 & 0.159 & 0.148 & 14.7 & & \\
\hline
\end{tabular}


TABle 7: Compressive strength loss rate after F-T cycles of RSFPC.

\begin{tabular}{lcccc}
\hline \multirow{2}{*}{ Mix ID } & \multicolumn{3}{c}{ Compressive strength loss rate (\%) } \\
& 25 F-T cycles & 50 F-T cycles & 75 F-T cycles & 100 F-T cycles \\
\hline WCR4 + SF12 & 2.1 & 5.1 & 12.7 & 19.4 \\
WCR6 + SF12 & 1.3 & 5.2 & 10.9 & 18.3 \\
WCR8 + SF12 & 1.0 & 5.0 & 10.1 & 15.6 \\
\hline
\end{tabular}

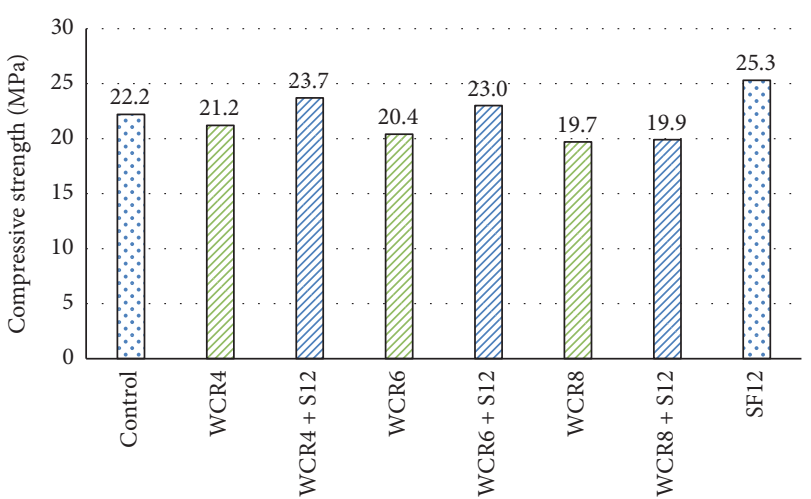

FIgURE 3: The compressive strength of RSFPC.

reinforcement of SF, RSFPC has higher compressive strength under the same WCR content. The addition of SF improves the strength of the cementitious material of the PC, thus making up for the adverse effect of WCR on the strength of the cementitious material. Although the compressive strengths of all groups are lower than that of the SF group, the compressive strengths of WCR $4+\mathrm{SF} 12$ and WCR6 + SF12 groups are more than $23 \mathrm{MPa}$, even higher than the control group. It indicates that the compound modification of WCR and SF for PC can meet certain compressive strength requirements. For unloaded and light pavement, such compressive strength is up to standard.

3.2.2. Flexural Strength. Figure 4 summarizes the flexural strength of RSFPC. It can be found that the flexural strengths of all RSFPC groups are higher than $4 \mathrm{MPa}$ and fully meet the standard requirement of 3.0 MPa in CJJ/T135-2009. The $\mathrm{WCR} 4+\mathrm{SF} 12$ and WCR6 + SF12 have similar flexural strength compared with the control group. Like compressive strength, the flexural strengths of all RSFPC groups are greater than those of the WCR groups under the same WCR contents. Compared with the SF group, with the variation of WCR content from $4 \%$ to $8 \%$, the RSFPC's flexural strength decreases $10 \%, 11 \%$, and $22 \%$, respectively. The influence mechanism of WCR and SF on the flexural strength of PC is the same as that of compressive strength. Although WCR is unfavorable to the flexural strength, this adverse effect can be reduced by the incorporation of $\mathrm{SF}$, and the flexural strength of RSFPC can reach the expected level.

3.2.3. Flexural Failure Strain. WCR is a kind of elastic material; the purpose of using WCR modification is to improve the deformability of PC. Figure 5 describes the flexural failure strain of RSFPC. It is obvious that the flexural failure strains of the WCR group and RSFPC are significantly higher than those of the control group and SF group. Due to the high elasticity, the addition of rubber makes the deformation of the PC better under the action of vehicle load, reducing the rigidity and improving the toughness of the PC. With the same amount of WCR, the flexural failure strain of the WCR group and RSFPC group are basically the same, which indicates that the WCR is the fundamental factor that creates the improvement of the flexural failure strain. Compared with the control group, the flexural failure strain of RSFPC is enhanced by $12 \%, 59 \%$, and $76 \%$, respectively. It means that the deformability of PC has been greatly improved, and when used as the road surface or base, PC has better fatigue properties under repeated loads.

3.2.4. Flexural Elastic Modulus. Figure 6 shows the flexural elastic modulus of RSFPC. The flexural elastic modulus of RSFPC decreases with the increasing WCR contents and it reveals that the addition of WCR makes the flexural elastic modulus aggravated. Based on the effects of WCR on the flexural strength and flexural failure strain above, on the one hand, the WCR reduces the flexural strength of PC and improves its flexural failure strain, on the other hand, thus reducing its flexural elastic modulus. RSFPC has higher flexural elastic modulus than that of the WCR group at the same WCR content because the flexural failure strain of the WCR group and RSFPC is basically the same at the same level of WCR content. However, due to the incorporation of $\mathrm{SF}$, the flexural strength of RSFPC increases, resulting in a higher flexural elastic modulus. Compared with the control group, the WCR4 + SF12 group has a flexural elastic modulus of $24 \mathrm{GPa}$ with a $5.3 \%$ increase, although there is a $15 \%$ decrease compared with the SF group. The flexural elastic modulus is closely related to the flexural strength and flexural failure strain, so the modification materials and its contents of RSFPC should be considered comprehensively based on its property indexes in practical application.

3.2.5. F-T Resistance. The F-T resistance is another vital index for RSFPC in seasonal frozen regions. The compressive strength loss rates of the control group, WCR group, RSFPC group, and SF group after different F-T cycles are presented in Figure 7. It is obvious that compared with the control group, the compressive strength loss rates of the WCR group, RSFPC group, and SF group under different F-T cycles are lower, which indicates that WCR modification, SF modification, and WCR and SF compound modification are all beneficial to F-T resistance of PC. The improvement of F-T resistance of PC by WCR is mainly attributed to the increase of $\mathrm{PC}$ deformation during the frost 


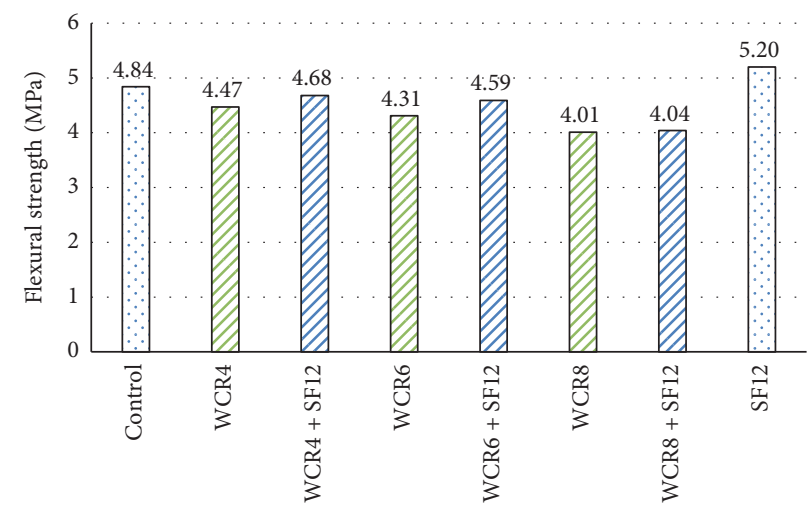

FIgURE 4: The flexural strength of RSFPC.

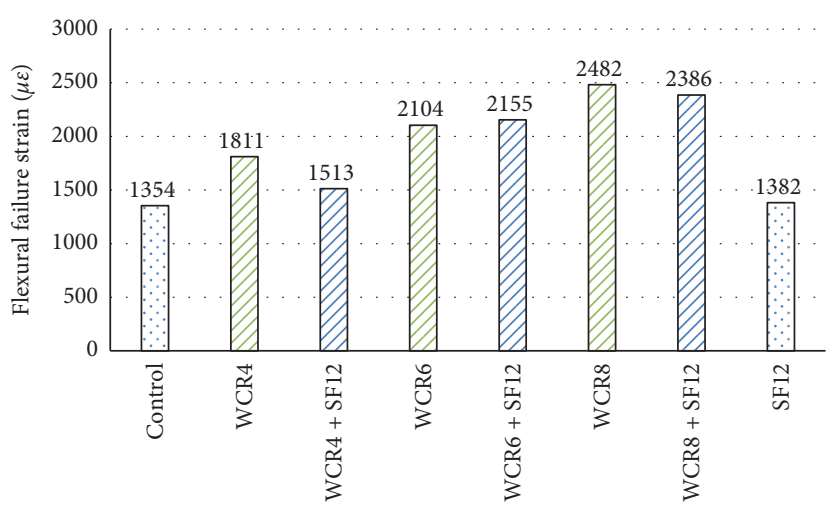

Figure 5: The flexural failure strain of RSFPC.

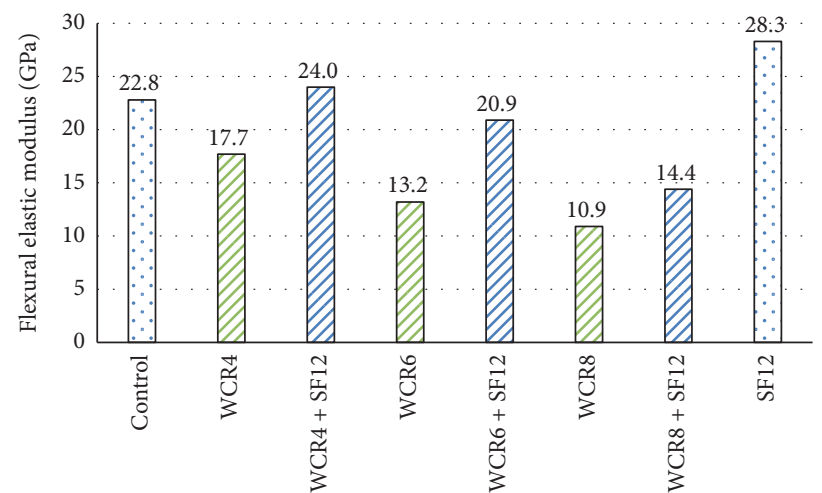

FIgURE 6: The flexural elastic modulus of RSFPC.

heaven. Moreover, the improvement of F-T resistance of PC by SF is because SF improves the strength of cementitious material and reduces the effectiveness of F-T damage. RSFPC group has lower compressive strength loss rates than that of WCR group with the same WCR content, which indicates that WCR and SF compound modification is better than the WCR single modification. However, compared with SF single modification, the compressive strength loss rate of WCR and SF composite modification is higher, indicating that the WCR and SF composite modification had poor F-T resistance. Although both SF and WCR can improve the F-T performance of PC, the WCR and SF composite modification is not the superposition of their single modification effect.

\section{Discussion}

For the road material, mechanical properties and durability are extremely important. It should not only have enough strength to bear the vehicle load but also have large deformability to resist the action of repeated load. For road materials in seasonal frozen regions, it should also have 


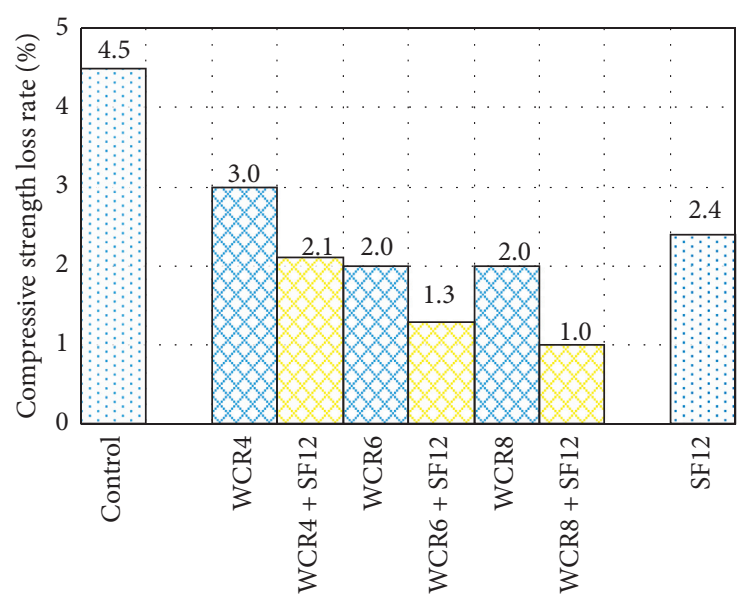

(a)

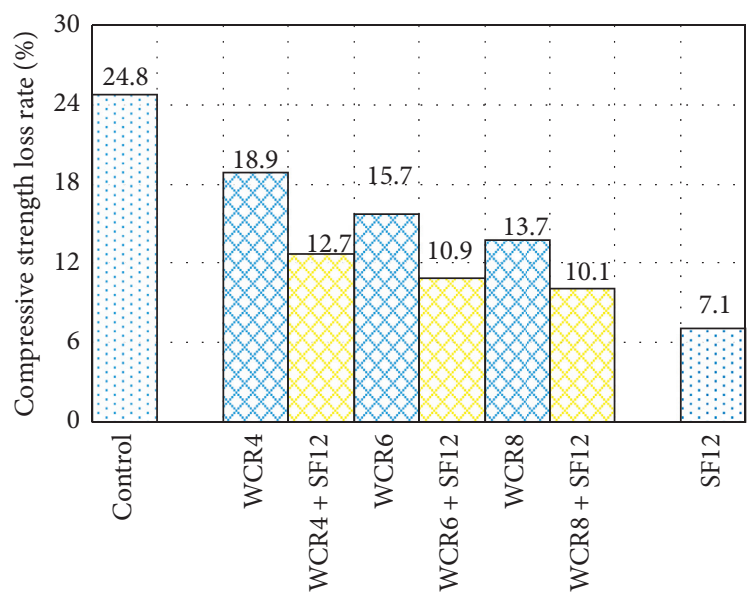

(c)

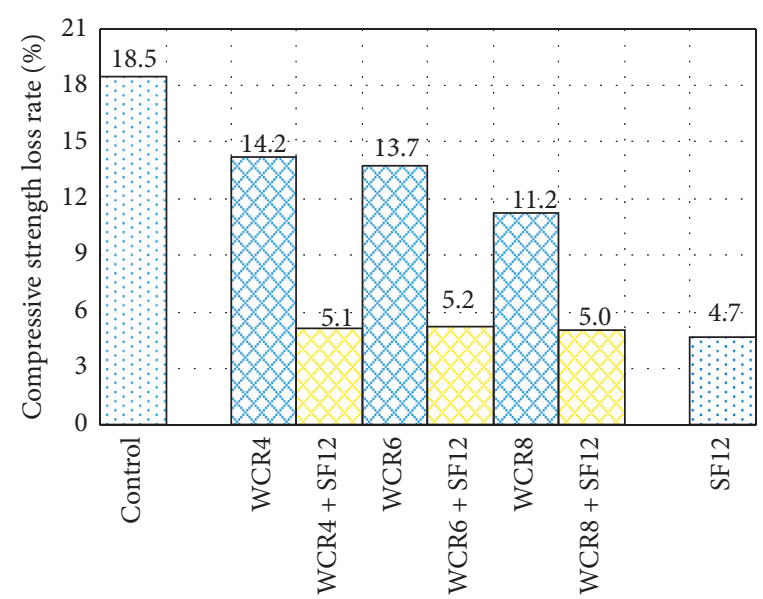

(b)

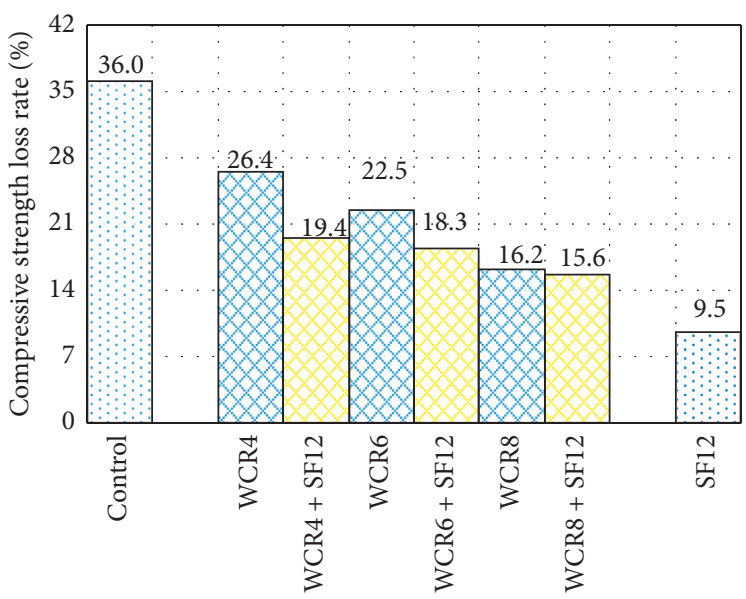

(d)

Figure 7: The compressive strength loss rate of RSFPC after different F-T cycles. (a) 25 F-T cycles; (b) 50 F-T cycles; (c) 75 F-T cycles; (d) 100 F-T cycles.

certain F-T durability; it requires that the material has comprehensive properties rather than being superior in one area and inferior in others. Due to the requirement of permeability, the porosity of PC is usually large. However, high porosity will cause a reduction in mechanical properties, such as compressive strength, flexural strength, and elastic modulus. In addition, too large porosity is very unfavorable to $\mathrm{F}-\mathrm{T}$ resistance, which will accelerate the damage of PC. Meanwhile, under the action of repeated load, $\mathrm{PC}$ is prone to fatigue damage and failure, and its deformability is an important index that affects its service life. Therefore, PC applied in practical engineering must have a certain strength, deformability, and F-T resistance.

In Section 3, the mechanical properties and F-T resistance are discussed in detail; all kinds of property indexes for RSFPC and other PC are presented in Figure 8 with a radar map. It can comprehensively compare the differences between various property indexes of different types of PC and select PC with superior comprehensive performance. Except for the compressive strength loss rate under F-T cycles, "the larger, the better" is another property index for PC. Figure 8 shows that RSFPC with $6 \%$ WCR content has the best comprehensive performance, followed by RSFPC with $4 \%$ WCR content. These two groups have better strength, greater deformability, and higher F-T resistance. The strength and F-T resistance of SF group are better, but the deformability is poor. The control group has poor F-T resistance and deformability, while WCR groups express lower strength and elastic modulus. Therefore, it is necessary to select the 


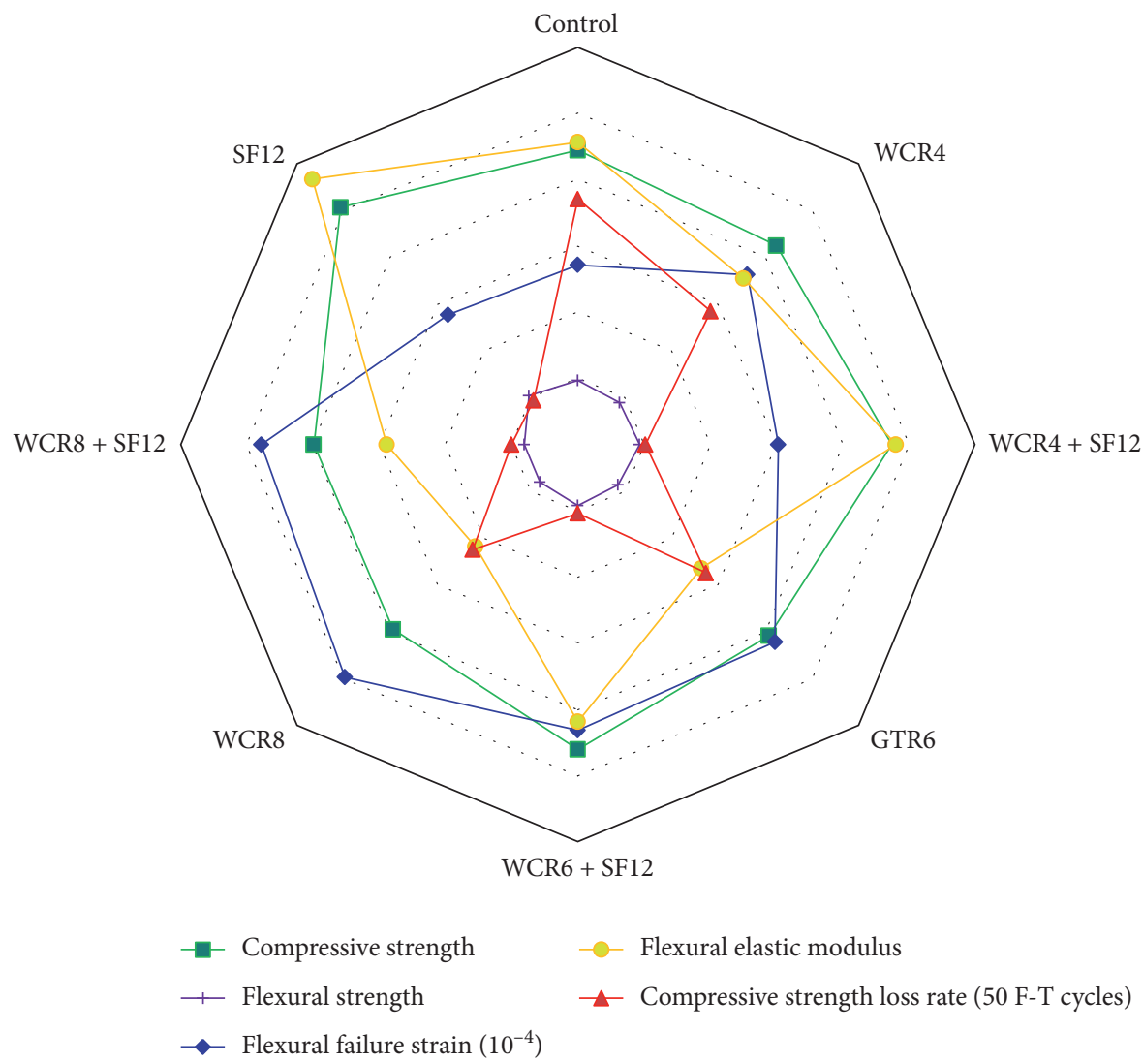

FIgURE 8: The radar map of properties for RSFPC.

modification type of PC reasonably according to the characteristics of practical projects and the requirements of material properties. RSFPC is recommended for the light load road in seasonal frozen regions.

\section{Conclusions}

In this article, the compressive strength, flexural strength, flexural failure strain, flexural elastic modulus, and F-T resistance of RSFPC were investigated. The composite modification effects of WCR and SF were analyzed.

(1) The flexural failure strain of PC indicates that WCR is the determining factor in improving the flexural deformability of PC.

(2) WCR has adverse effects on the strength and elastic modulus of PC, but these adverse effects can be improved by the addition of SF. Compared with the control group, the WCR and SF composite modification can not only guarantee the strength characteristics of PC but also enhance the F-T resistance to some extent and, at the same time, significantly improve deformability of PC.

(3) Although both SF and WCR are advantageous to the F-Tresistance of PC, the improvement effect of WCR and SF composite modification is not the superposition of both, which is mainly because of their different effects on the mechanical properties of PC.
(4) Considering the mechanical properties, deformability, and F-T resistance of PC, the systematic comparison of different modification PC shows that RSFPC has a more balanced and comprehensive performance and is suggested to be the first choice in engineering application.

\section{Data Availability}

The data used to support the findings of this study are included within the article.

\section{Conflicts of Interest}

The authors declare that they have no conflicts of interest.

\section{Authors' Contributions}

G. B. Luo contributed to conceptualization, formal analysis, and investigation. P. Zhao was responsible for the methodology and writing, reviewing, and editing of the manuscript. Y. P. Zhang wrote and prepared the original draft. Z. Z. Xie was responsible for funding acquisition and formal analysis.

\section{Acknowledgments}

This research was supported by the Guangxi Key Science and Technology Project (Grant no. AB17292032). The authors 
would like to express their appreciation to the Road and Bridge Laboratory of Jilin University for support during the experiment.

\section{References}

[1] J. Y. Zhao, L. Yu, and Y. D. Xu, "Exploring difference in land surface temperature between the city centres and urban expansion areas of china's major cities," International Journal of Remote Sensing, vol. 41, pp. 8963-8983, 2020.

[2] L. J. Lin, T. Gao, M. Luo et al., "Contribution of urbanization to the changes in extreme climate events in urban agglomerations across china," The Science of the Total Environment, vol. 744, Article ID 140264, 2020.

[3] S. Adams, E. Boateng, and A. O. Acheampong, "Transport energy consumption and environmental quality: does urbanization matter?" The Science of the Total Environment, vol. 744, Article ID 140617, 2020.

[4] A. J. Echendu, "The impact of flooding on Nigeria's sustainable development goals (SDGs)," Ecosystem Health and Sustainability, vol. 6, 2020.

[5] H. D. Lv, L. Yang, J. S. Zhou et al., "Water resource synergy management in response to climate change in China: from the perspective of urban metabolism," Resources, Conservation and Recycling, vol. 163, Article ID 105095, 2020.

[6] P. Roy, S. C. Pal, R. Chakrabortty, I. Chowdhuri, S. Malik, and B. Das, "Threats of climate and land use change on future flood susceptibility," Journal of Cleaner Production, vol. 272, Article ID 122757, 2020.

[7] M. Santamouris and G. Y. Yun, "Recent development and research priorities on cool and super cool materials to mitigate urban heat island," Renewable Energy, vol. 161, pp. 792-807, 2020.

[8] E. Forero-Ortiz, E. Martinez-Gomariz, M. C. Porcuna, L. Locatelli, and B. Russo, "Flood risk assessment in an underground railway system under the impact of climate change: a case study of the Barcelona metro," Sustainability, vol. 12, p. 5291, 2020.

[9] M. T. Sohail, Y. Mahfooz, K. Azam, Y. Yen, G. F. Liao, and S. Fahad, "Impacts of urbanization and land cover dynamics on underground water in Islamabad, Pakistan," Desalination and Water Treatment, vol. 159, pp. 402-411, 2019.

[10] K.-Y. Park and M.-H. Lee, "Ulnerability analysis of urban district on the urban flood damage: a case study," Desalination and Water Treatment, vol. 119, pp. 27-35, 2018.

[11] Y. C. Ma, Y. Jiang, and S. Swallow, "China's sponge city development for urban water resilience and sustainability: a policy discussion," The Science of the Total Environment, vol. 729, Article ID 139078, 2020.

[12] J. W. Liu, H. Li, Y. Wang, and H. J. Zhang, "Integrated life cycle assessment of permeable pavement: model development and case study," Transport Research Part D-Transport and Environment.vol. 85, Article ID 102381, 2020.

[13] M. Brugin, M. Marchioni, G. Becciu, F. Giustozzi, E. Toraldo, and V. C. Andres-Valeri, "Clogging potential evaluation of porous mixture surfaces used in permeable pavement systems," European Journal Environmental Civil Engineering, vol. 24, pp. 620-630, 2020.

[14] H. El-Hassan, P. Kianmehr, and S. Zouaoui, "Properties of pervious concrete incorporating recycled concrete aggregates and slag," Construction and Building Materials, vol. 212, pp. 164-175, 2020.

[15] M. Saaly, M. M. Hedayat, and A. Golroo, "Performance of pervious concrete pavement under various raining conditions," Road Materials and Pavement Design, vol. 20, pp. 1653-1663, 2019.

[16] M. Seslija, N. Radovic, D. Jovanov, D. Kukaras, A. StarcevCurcin, and I. Jokanovic, "Possibilities of pervious concrete application in road construction," Tehnički Vjesnik, vol. 25, pp. 1202-1212, 2018.

[17] S. Kant Sahdeo, G. D. Ransinchung R.N., K. L. Rahul, and S. Debbarma, "Effect of mix proportion on the structural and functional properties of pervious concrete paving mixtures," Construction and Building Materials, vol. 255, Article ID 119260, 2020.

[18] H. B. Liu, G. B. Luo, H. B. Wei, and H. Yu, "Strength, permeability, and freeze thaw durability of pervious concrete with different aggregate sizes, porosities, and water-binder ratios," Applied Sciences, vol. 8, p. 1217, 2018.

[19] L. Moretti, P. Di Mascio, and C. Fusco, "Porous concrete for pedestrian pavements," Water, vol. 11, p. 2105, 2019.

[20] F. Yu, D. Q. Sun, J. Wang, and M. J. Hu, "Influence of aggregate size on compressive strength of pervious concrete," Construction and Building Materials, vol. 209, pp. 463-475, 2019.

[21] H. B. Liu, G. B. Luo, P. L. Zhou, H. B. Wei, W. J. Li, and D. Yu, "Flexural-fatigue properties of sustainable pervious concrete pavement material containing ground tire rubber and silica fume," Sustainability, vol. 11, p. 4467, 2019.

[22] M. S. M. Lund, J. T. Kevern, V. R. Schaefer, and K. K. Hansen, "Mix design for improved strength and freeze thaw durability of pervious concrete fill in Pearl-chain bridges," Materials and Structures, vol. 50, no. 1, p. 42, 2017.

[23] M. Vancura, K. MacDonald, and L. Khazanovich, "Microscopic analysis of paste and aggregate distresses in pervious concrete in a wet, hard freeze climate," Cement and Concrete Composites, vol. 33, no. 10, pp. 1080-1085, 2011.

[24] O. Youssf, J. E. Mills, T. Benn et al., "Development of crumb rubber concrete for practical application in the residential construction sector-design and processing," Construction and Building Materials, vol. 260, Article ID 119813, 2020.

[25] J. Mo, L. Zeng, Y. Liu et al., "Mechanical properties and damping capacity of polypropylene fiber reinforced concrete modified by rubber powder," Construction and Building Materials, vol. 242, Article ID 118111, 2020.

[26] A. S. Eisa, M. T. Elshazli, and M. T. Nawar, "Experimental investigation on the effect of using crumb rubber and steel fibers on the structural behavior of reinforced concrete beams," Construction and Building Materials, vol. 252, Article ID 119078, 2020.

[27] Y. Li, S. Zhang, R. J. Wang, and F. N. Dang, "Potential use of waste tire rubber as aggregate in cement concrete: a comprehensive review," Construction and Building Materials, vol. 225, pp. 1183-1201, 2019.

[28] W. Gardziejczyk, A. Plewa, and R. Pakholak, "Effect of addition of rubber granulate and type of modified binder on the viscoelastic properties of stone mastic asphalt reducing tire/ road noise (SMA LA)," Materials, vol. 13, p. 3446, 2020.

[29] Y. S. Wang, Z. H. Xu, J. B. Wang, Z. H. Zhou, P. Du, and $\mathrm{X}$. Cheng, "Synergistic effect of nano-silica and silica fume on hydration properties of cement-based materials," Journal of Thermal Analysis and Calorimetry, vol. 140, pp. 2225-2235, 2019.

[30] H. B. Liu, G. B. Luo, L. H. Wang, W. S. Wang, W. J. Li, and Y. F. Gong, "Laboratory evaluation of eco-friendly pervious concrete pavement material containing silica fume," Applied Sciences, vol. 9, p. 73, 2019. 
[31] R. Shirdam, M. Amini, and N. Bakhshi, "Investigating the effects of copper slag and silica fume on durability, strength, and workability of concrete," International Journal of Environmental Research, vol. 13, pp. 909-924, 2019.

[32] M. H. Mizan, T. Ueda, and K. Matsumoto, "Enhancement of the concrete-PCM interfacial bonding strength using silica fume," Construction and Building Materials, vol. 259, Article ID 119774, 2020.

[33] S. Mondal and K. P. Biligiri, "Crumb rubber and silica fume inclusions in pervious concrete pavement systems: evaluation of hydrological, functional, and structural properties," Journal of Testing and Evaluation, vol. 46, pp. 892-905, 2018.

[34] M. Gesoglu, E. Guneyisi, G. Khoshnaw, and S. Ipek, "Investigating properties of pervious concretes containing waste tire rubbers," Construction and Building Materials, vol. 63, pp. 206-213, 2014.

[35] H. B. Liu, G. B. Luo, Y. F. Gong, and H. B. Wei, "Mechanical properties, permeability, and freeze thaw resistance of pervious concrete modified by waste crumb rubbers," Applied Sciences, vol. 8, p. 1843, 2018.

[36] A. A. Aliabdo, A. M. Abd Elmoaty, and A. M. Fawzy, "Experimental investigation on permeability indices and strength of modified pervious concrete with recycled concrete aggregate," Construction and Building Materials, vol. 193, pp. 105-127, 2018.

[37] D. A. Mann, "The effects of utilizing silica fume in portland cement pervious concrete," University of Missouri-Kansas City, Kansas, Misssouri, USA, Master of Science, 2014.

[38] P. T. A. Zerdi, M. A. Samee, H. Ali, and T. Zerdi, "Study of silica fume incorporation in pervious concrete," International Journal of Science and Research, vol. 5, pp. 532-533, 2016.

[39] G. Adil, J. T. Kevern, and D. Mann, "Influence of silica fume on mechanical and durability of pervious concrete," Construction and Building Materials, vol. 247, Article ID 118453, 2020.

[40] Ministry of Housing and Urban-Rural Construction of the People's Republic of China, Technical Specification for Pervious Cement Concrete Pavement, Ministry of Housing and Urban-Rural Construction of the People's Republic of China, Beijing, China, 2009, in Chinese.

[41] Ministry of Housing and Urban-Rural Construction of the People's Republic of China, Standard for Test Method of Mechanical Properties on Ordinary Concrete, Ministry of Housing and Urban-Rural Construction of the People's Republic of China, Beijing, China, 2002, in Chinese.

[42] Ministry of Housing and Urban-Rural Construction of the People's Republic of China, Standard for Test Methods of Long-Term Performance and Durability of Ordinary Concrete, Ministry of Housing and Urban-Rural Construction of the People's Republic of China, Beijing, China, 2009, in Chinese. 